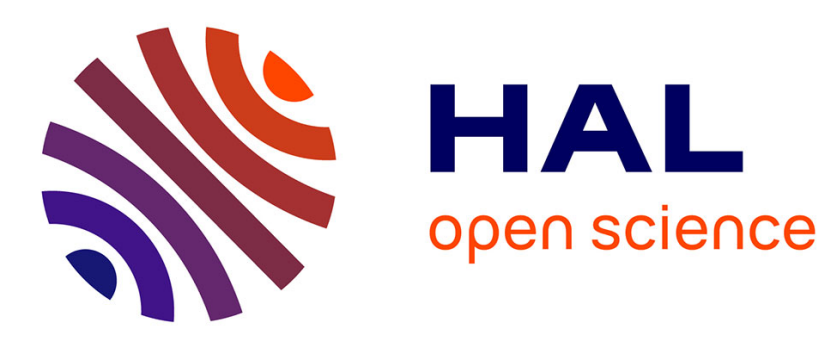

\title{
The transition in hydrogen sensing behavior in noncontinuous palladium films
}

Thomas Keiffer, Guillermo Villanueva, Frédéric Fargier, Frédéric Favier, Juergen Brugger

\section{- To cite this version:}

Thomas Keiffer, Guillermo Villanueva, Frédéric Fargier, Frédéric Favier, Juergen Brugger. The transition in hydrogen sensing behavior in noncontinuous palladium films. Applied Physics Letters, 2010, 97, pp.121911. 10.1063/1.3491263 . hal-00560506

\section{HAL Id: hal-00560506 https://hal.science/hal-00560506}

Submitted on 5 Jul 2021

HAL is a multi-disciplinary open access archive for the deposit and dissemination of scientific research documents, whether they are published or not. The documents may come from teaching and research institutions in France or abroad, or from public or private research centers.
L'archive ouverte pluridisciplinaire HAL, est destinée au dépôt et à la diffusion de documents scientifiques de niveau recherche, publiés ou non, émanant des établissements d'enseignement et de recherche français ou étrangers, des laboratoires publics ou privés. 


\title{
The transition in hydrogen sensing behavior in noncontinuous palladium films
}

\author{
Thomas Kiefer, ${ }^{1, a)}$ Luis Guillermo Villanueva, ${ }^{1}$ Frédéric Fargier, ${ }^{2}$ Frédéric Favier, ${ }^{2, b)}$ and \\ Jürgen Brugger ${ }^{1, c)}$ \\ ${ }_{1}^{1}$ Microsystems Laboratory, École Polytéchnique Fédérale de Lausanne (EPFL), Lausanne 1015, Switzerland \\ ${ }^{2}$ Institut Charles Gerhardt, AIME, UMR 5253, CNRS-Université Montpellier 2, cc1502, 34095 \\ Montpellier Cedex 05, France
}

(Received 27 July 2010; accepted 27 August 2010; published online 22 September 2010)

\begin{abstract}
The morphological transition in ultrathin palladium (Pd) films around the percolation threshold and the related transition in hydrogen sensing behavior is investigated. We find that besides the transition from continuous to discontinuous Pd, an intermediate - semicontinuous-state must be considered. It shows hydrogen sensing features of both continuous and discontinuous film types, simultaneously. This study focuses on the discontinuous-semicontinuous transition. Experimental evidence is supported by studying the evolution of the electrical resistance with temperature, under hydrogen exposure and after thermal annealing. The results are highly relevant for the optimization of nanogap based hydrogen sensors. (C) 2010 American Institute of Physics. [doi:10.1063/1.3491263]
\end{abstract}

Ultrathin metal films have been of interest in research for decades. ${ }^{1,2}$ They usually consist of randomly distributed isolated or partly connected islands that are separated by nanoscopic gaps of less than a few nanometers. They are commonly formed at the early stages of film growth during physical vapor deposition such as evaporation or sputtering. ${ }^{3,4}$ In particular ultrathin palladium (Pd) films have been recently attracting increased attention as an application in resistive hydrogen $\left(\mathrm{H}_{2}\right)$ gas sensing for fuel cell safety systems. ${ }^{5,6}$ Here, the volume expansion that occurs in $\mathrm{Pd}$ nanoclusters at hydrogenation ${ }^{7,8}$ is exploited to reversibly narrow or even close the film-inherent nanogaps. New percolation pathways are thus formed and lead to a decrease in electrical resistance [see Fig. 1(a)]. This is in contrast to common $\mathrm{H}_{2}$ sensors using bulk $\mathrm{Pd}$, where the increased scattering of conducting electrons at absorbed interstitial $\mathrm{H}$-atoms gives rise to an increase in electrical resistivity. $^{9-11}$

To optimize such sensors based on ultrathin Pd films, a precise understanding of the electric transport mechanisms and hydrogen sensing behavior as a function of the morphology is essential. The existence of distinct $\mathrm{H}_{2}$ sensing behavior for continuous and entirely discontinuous $\mathrm{Pd}$ structures has been previously reported using various substrate materials such as $\mathrm{HOPG},{ }^{8} \mathrm{Si},{ }^{12} \mathrm{SiO}_{2},{ }^{5} \mathrm{Si}_{3} \mathrm{~N}_{4}$ (Ref. 13) or selfassembled monolayers. ${ }^{6}$ However, the characteristics of the interjacent transition regime itself and related changes in electrical response to hydrogen have not been studied yet. Our investigations show that this transition is of a gradual nature and is characterized by a semicontinuous film regime $^{2,14}$ that results in characteristic physical properties and distinct responses at $\mathrm{H}_{2}$ exposure. The semicontinuous state is characterized by the presence of interconnected islands forming continuous metallic pathways isolated by a large fraction of nanogaps [see Fig. 1(b)]. At $\mathrm{H}_{2}$ exposure, a superposition of characteristic electronic signals from both

\footnotetext{
${ }^{a}$ Electronic mail: thomas.kiefer@epfl.ch.

${ }^{b)}$ Electronic mail: fredf@univ-mont2.fr.

${ }^{c)}$ Electronic mail: juergen.brugger@epfl.ch.
}

continuous and discontinuous type films was observed that each or the other gradually gain influence when the continuous or discontinuous limit is approached. The electrical properties of the films were studied with regard to temperature, $\mathrm{H}_{2}$ exposure and thermal annealing. It allowed to clearly distinguish between films having either a discontinuous or semicontinuous morphology.

Ultrathin Pd films were deposited by electron-beam evaporation at room temperature and an evaporation rate of $0.1 \AA / \mathrm{s}$ on supporting polymer (SU8) layers. SU8 is a widely used epoxy based negative tone resist with a high chemical stability. The films were contacted by $400 \mu \mathrm{m}$ spaced aluminum microelectrodes. Thereto, stencil lithography ${ }^{15}$ was used to preserve the as-deposited properties of the Pd films. The considered range of nominal thicknesses of the Pd film was between $1.4 \mathrm{~nm}$ and $2.5 \mathrm{~nm}$, which was slightly below and above the percolation threshold, respectively. The grain size of the Pd film was estimated to be below $10 \mathrm{~nm}$. Atomic force microscopy of the SU8 revealed a surface roughness of about $2 \mathrm{~nm}$, which did not permit to clearly resolve a change in contrast between a bare and a Pd-covered surface. Consequently, the film morphology itself

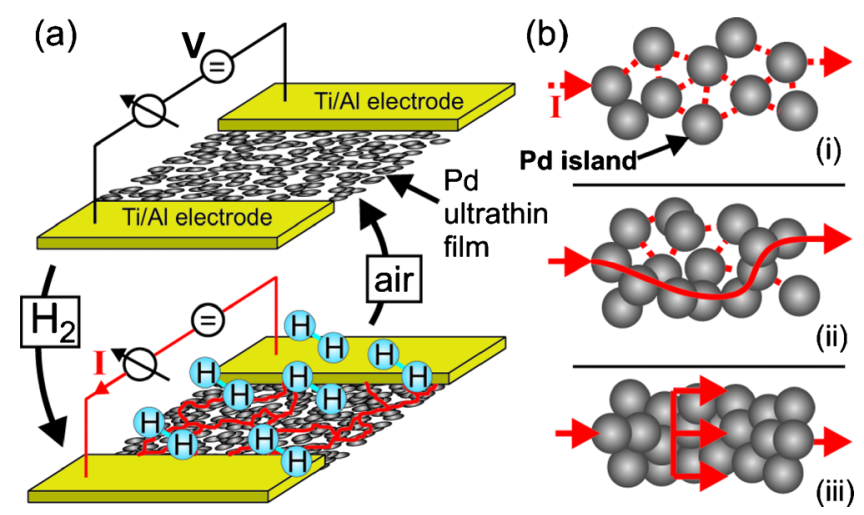

FIG. 1. (Color online) (a) $\mathrm{H}_{2}$ sensing principle: the volume expansion of palladium $(\mathrm{Pd})$ islands creates electrical percolation pathways through the film. (b) Ultrathin film types: (i) discontinuous, no conduction or conduction by quantum tunneling, (ii) semicontinuous, mixed tunneling and metallic conduction, and (iii) continuous, metallic conduction. 

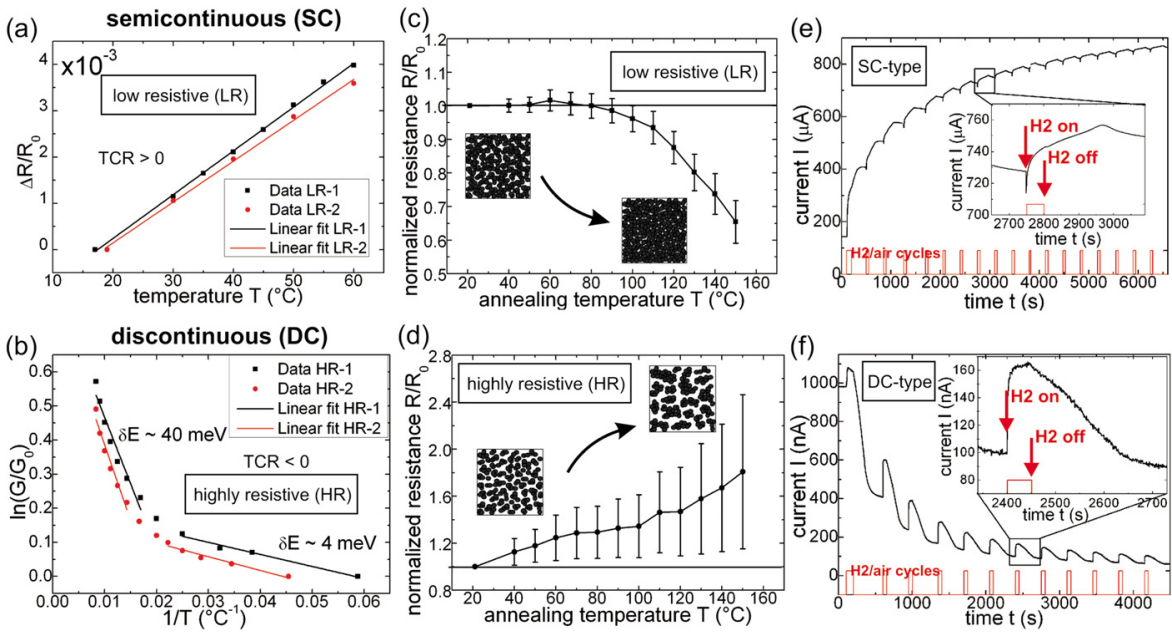

(d)
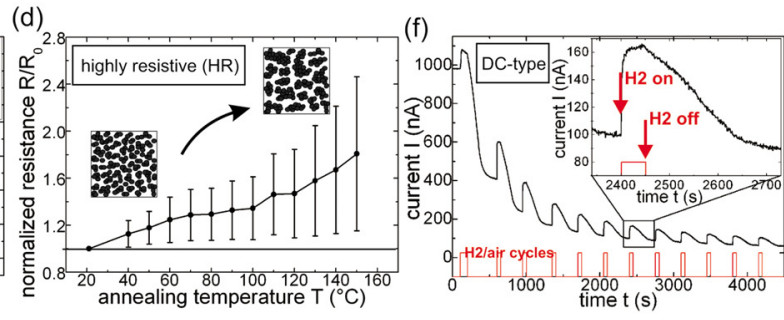

FIG. 2. (Color online) Characteristics of $[(a),(c)$, and (e)] semicontinuous and $[(b),(d)$, and (f)] discontinuous Pd films on supporting SU8 layers: [(a) and (b)] resistance-temperature relationship for each two films, [(c) and (d)] electrical resistance after thermal annealing, [(e) and (f)] typical sensor response and recovery during alternating $4 \% \mathrm{H}_{2}$ /air cycles $\left(50 \mathrm{~s} \mathrm{H}_{2}\right.$ exposure time and $300 \mathrm{~s}$ desorption time in air, $\mathrm{V}=1 \mathrm{~V}$ ). could not be used as a characteristic measure for the initial film state. Instead, we used the initial electrical resistance $R_{0}$ or conductance $G_{0}$ in air as an indirect measure readily accessible. To obtain a repeatable response, the sensors were exposed to several cycles of $\mathrm{H}_{2}$ /air prior to $\mathrm{H}_{2}$ measurements. Details on fabrication and characterization methods are presented in the supplementary information. ${ }^{16}$

Two sets of films were prepared for $\mathrm{H}_{2}$ measurements: low resistive films (LR-type, $R_{0}<16 \mathrm{k} \Omega$ ) with nominal thicknesses between 1.5 and $2.5 \mathrm{~nm}$, and highly resistive films (HR-type, $R_{0}>52 \mathrm{k} \Omega$ ) with nominal thicknesses of about $1.4-1.5 \mathrm{~nm}$. The large jump in $R_{0}$ around $1.5 \mathrm{~nm}$ film thickness is associated with the percolation threshold. ${ }^{2}$ Electrical resistivities for LR-type films were at least 3.5 to 4.8 $\times 10^{-6} \Omega \mathrm{m}$, i.e., more than one order of magnitude higher as compared to a respective $10 \mathrm{~nm}$ thick Pd film which was about $0.28 \times 10^{-6} \Omega \mathrm{m}$. This increase in resistivity results from the presence of gaps in the film that create not only a larger fraction of metal/air interfaces but also a reduced effective cross sectional area for electron transport. Currentvoltage (IV) measurements were linear for both types of films without hysteresis or polarity-dependence for biases up to several volts which indicates homogenous electrode/film interfaces. ${ }^{17}$ However, electric transport across a nanogap which is described by quantum tunneling, only presents linear IV behavior for small enough biases $\mathrm{V}$ approaching $0 \mathrm{~V}$ that do not alter the height of the energy barrier. ${ }^{18}$ This discrepancy can be explained by the distribution of the external bias into small potential drops across the multitude of nanogaps within a discontinuous film. ${ }^{19,20}$ An individual tunnel junction will then still be in the low bias regime.

To clearly relate a given $R_{0}$ to either a semicontinuous or a discontinuous film type prior to $\mathrm{H}_{2}$ measurements, we studied the evolution of $R_{0}$ with the temperature ${ }^{14}$ and after thermal annealing. ${ }^{1}$ The temperature coefficient of resistance (TCR) can give evidence about the electric transport mechanism prevailing within the film. ${ }^{2,14}$ In a continuous metallic structure, the increased electron scattering at higher temperatures gives rise to an increase in electrical resistance. ${ }^{14,21}$ With the presence of nanogaps, thermally activated quantum tunneling as a transport mechanism comes into play ${ }^{1}$ which is characterized by $\ln \left(I / I_{0}\right) \propto-\delta E /\left(k_{B} T\right)$, where $T$ is the temperature and $\delta E$ is the activation energy. When a continuous metal film passes into the semicontinuous state the TCR decreases gradually, ${ }^{14}$ until a negative TCR is eventually ob- served where the film becomes discontinuous. Note that electrical transport might occur through the substrate by electron hopping rather than direct tunneling across the air-gaps if these are comparably large. ${ }^{19,22} \delta E$ then depends on the specific substrate properties. Figures 2(a) and 2(b) show typical temperature measurements for both types of Pd films. For the two LR-type films (LR-1/-2) in Fig. 2(a) the relative change in resistance with temperature is about $d\left(\Delta R / R_{0}\right) / d T \approx 9$ $\times 10^{-5} \mathrm{~K}^{-1}$. This is about an order of magnitude lower than the bulk value of $8.5 \times 10^{-4} \mathrm{~K}^{-1}$ and indicates semicontinuity. ${ }^{14}$ For the two HR-type films (HR-1/-2) in Fig. 2(b) a negative TCR is found, thus they are discontinuous. $\delta E$ varies with the temperature range, which is visible by the change in slope of the graphs in Fig. 2(b). We interpret this behavior by the domination of different conduction mechanisms through the polymer layer and the metal film itself.

Electrical resistance measurements at room temperature were performed before and after thermal annealing in air at various temperatures. As a reference, a continuous $\mathrm{Pd}$ wire with a thickness of $50 \mathrm{~nm}$ was annealed which did not show any change in $R_{0}$ up to $350{ }^{\circ} \mathrm{C}$ annealing temperature. Above, a rapid increase in $R_{0}$ indicates the formation of $\mathrm{PdO}$. The normalized resistances as a function of annealing temperature are shown in Fig. 2(c) for LR-type films and (d) for HR-type films. The LR-type films show a decrease in $R_{0}$ which can be explained by coalescence models, where initially separated islands come into closer contact with each other. ${ }^{1}$ In HR-type films, which have a lower metal island density, an increase in $R_{0}$ is observed. Agglomeration processes cause initially connected islands to break apart which counteracts the coalescence process. ${ }^{1,5}$ These distinct differences between both sets of films identify low resistive films with a semicontinuous (SC) type and highly resistive films with a discontinuous (DC) type film morphology.

Both semicontinuous and discontinuous Pd films were exposed to alternating $\mathrm{H}_{2}$ / air cycles with a $\mathrm{H}_{2}$ concentration of $4 \%$. Representative current/time diagrams are shown in Figs. 2(e) and 2(f). The response to $\mathrm{H}_{2}$ of the DC-type film in graph (f) shows an immediate increase in current and reaches its equilibrium within a few seconds. The recovery in air occurs instantaneously and finds its baseline after several tens of seconds. The SC-type film in (e) shows a superposition of both decreasing (the under-spike at $\mathrm{H}_{2}$ on) and increasing conductance. It indicates that a superposition of 
(a) $\sim 1.5 \mathrm{~nm}$

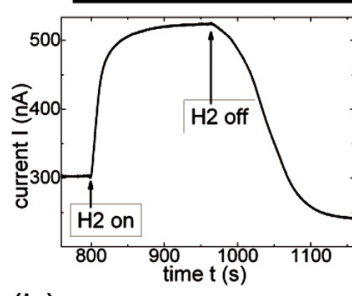

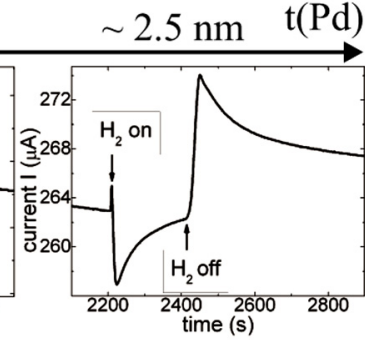

(b)

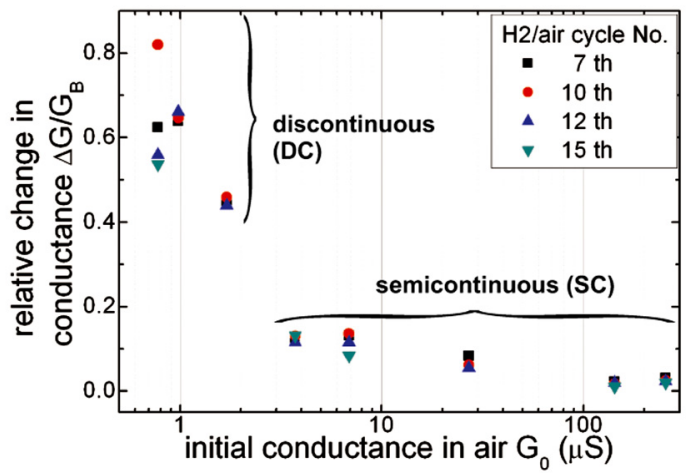

FIG. 3. (Color online) (a) Typical electrical signals obtained at $\mathrm{H}_{2}$ exposure for various film thicknesses (b) Relative change in electrical conductance at $4 \% \mathrm{H}_{2} / \mathrm{N}_{2}$ exposure as a function of the initial sensor conductance $G_{0}$ in air. The transition between discontinuous and semicontinuous state occurs between 2 and $3 \mu \mathrm{S}$. V $=1 \mathrm{~V}$. electronic (conductance drop) and mechanical effects (conductance increase) takes place. The slow recovery which was observed for all SC-type films could be due to several effects: (i) the retarded desorption of $\mathrm{H}_{2}$ which is bound in deep energy traps in grain boundaries, (ii) a disadvantageous mechanical relaxation due to interlocking of metal grains, and (iii) slow grain boundary diffusion. ${ }^{23}$ For increasing film thicknesses $t_{P d}$ i.e., increasing $G_{0}$ in the semicontinuous state, the electronic effect becomes increasingly visible as more connected metallic paths are added to the system [see typical signals in Fig. 3(a)]. The evidence of the electronic effect in the signal vanishes completely for DC-type films below $t_{\mathrm{Pd}} \leq 1.5 \mathrm{~nm}$. It can be associated with the loss of last connected paths which brings the system below the percolation threshold. A qualitative model that we recently used to describe similar superimposed effects in single nanogaps ${ }^{11}$ also applies for the interpretation of the present observations. Depending on the time scales of both effects, a variety of signal shapes can be anticipated. For DC-type films the change in resistivity of isolated islands still takes place but its influence becomes invisible once that metallic conduction disappears.

Figure 3(b) shows the relative change in conductance $\Delta G / G_{B}$ with respect to the baseline current $G_{B}$ at each cycle for sensor responses to $\mathrm{H}_{2}$ as a function of $G_{0}$. It reveals a clear trend of increasing $\Delta G / G_{B}$ with increasing film discontinuity. It reflects the increasing influence of the mechanical effect in the conduction change at $\mathrm{H}_{2}$ exposure and confirms the previous findings.

We conclude that the transition from discontinuous-type to continuous-type $\mathrm{H}_{2}$ sensing behavior in ultrathin Pd films must be extended by an intermediate, semicontinuous state. It is characterized by the presence of competing contributions of electronic and $\mathrm{Pd}$ expansion effects at $\mathrm{H}_{2}$ exposure. Our results refine previous findings on this transition which is of importance for further developments of nanogap based hydrogen sensors.
The authors thank the FP6 Integrated Project HySYS under Project No. SES6-019981 for financial support, the Center of MicroNanofabrication (CMI) in Lausanne for technical support and Dr. Michel Rossi for the kind supply with equipment.

${ }^{1}$ J. R. Morris and T. J. Coutts, Thin Solid Films 47, 3 (1977).

${ }^{2}$ I. Rycroft and B. L. Evans, Thin Solid Films 290-291, 283 (1996).

${ }^{3}$ J. E. Morris, Vacuum 50, 107 (1998).

${ }^{4}$ C. Ratsch and J. A. Venables, J. Vac. Sci. Technol. A 21, S96 (2003).

${ }^{5}$ O. Dankert and A. Pundt, Appl. Phys. Lett. 81, 1618 (2002).

${ }^{6}$ T. Xu, M. P. Zach, Z. L. Xiao, D. Rosenmann, U. Welp, W. K. Kwok, and G. W. Crabtree, Appl. Phys. Lett. 86, 203104 (2005).

${ }^{7}$ F. A. Lewis, The Palladium Hydrogen System (Academic, New York, 1976).

${ }^{8}$ F. Favier, E. C. Walter, M. P. Zach, T. Benter, and R. M. Penner, Science 293, 2227 (2001).

${ }^{9}$ A. L. Cabrera and R. Aguayo-Soto, Catal. Lett. 45, 79 (1997).

${ }^{10}$ P. Offermans, H. D. Tong, C. J. M. van Rijn, P. Merken, S. H. Brongersma, and M. Crego-Calama, Appl. Phys. Lett. 94, 223110 (2009).

${ }^{11}$ T. Kiefer, F. Favier, O. Vazquez-Mena, G. Villanueva, and J. Brugger, Nanotechnology 19, 125502 (2008).

${ }^{12}$ G. Kaltenpoth, P. Schnabel, E. Menke, E. C. Walter, M. Grunze, and R. M. Penner, Anal. Chem. 75, 4756 (2003).

${ }^{13}$ M. Ramanathan, G. Skudlarek, H. H. Wang, and S. B. Darling, Nanotechnology 21, 125501 (2010).

${ }^{14}$ D. S. Campbell and A. R. Morley, Rep. Prog. Phys. 34, 283 (1971).

${ }^{15}$ J. Brugger, J. Berenschot, S. Kuiper, W. Nijdam, B. Otter, and M. Elwenspoek, Microelectron. Eng. 53, 403 (2000).

${ }^{16}$ See supplementary material at http://dx.doi.org/10.1063/1.3491263 for details on sensor fabrication and characterization methods for hydrogen measurements.

${ }^{17}$ P. Borziak, V. Dyukov, A. Kostenko, Y. Kulyupin, and S. Nepijko, Thin Solid Films 36, 21 (1976).

${ }^{18}$ J. G. Simmons, J. Appl. Phys. 34, 238 (1963).

${ }^{19}$ R. M. Hill, Proc. R. Soc. London, Ser. A 309, 397 (1969).

${ }^{20}$ C. A. Neugebauer and M. B. Webb, J. Appl. Phys. 33, 74 (1962).

${ }^{21}$ C. Reale, J. Mater. Sci. 6, 33 (1971).

${ }^{22}$ R. M. Hill, Proc. R. Soc. London, Ser. A 309, 377 (1969).

${ }^{23}$ T.-S. Kê, Phys. Rev. 71, 533 (1947). 